\title{
Expression of 1B capsid protein of Foot-and-mouth disease virus (FMDV) using baculovirus expression system and its validation in detecting SAT 2- specific antisera
}

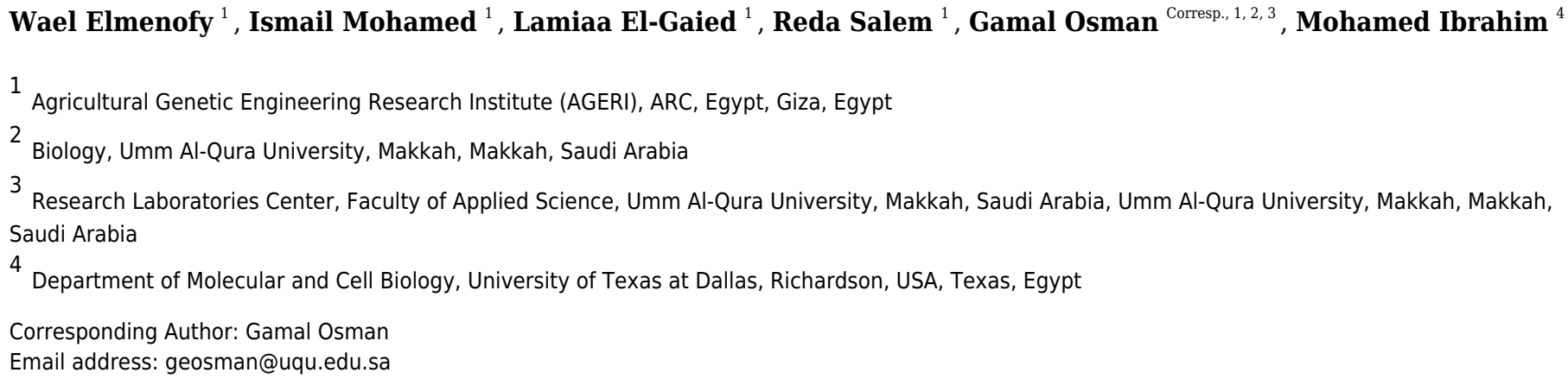

Foot-and-mouth disease virus (FMDV) is one of the most devastating animal viruses that affect the livestock worldwide. The 1B capsid of FMDV has been widely used to detect and confirm the infection. In the present study, the sequence coding for 1B subunit of FMDV capsid was expressed in insect cells using the baculovirus expression system under the polyhedrin (polh) promoter. The expression of 1B capsid protein was validated in the culture filtrate of insect cells using SDS-PAGE and western blotting. The culture filtrate containing recombinant $1 \mathrm{~B}$ capsid ( $\mathrm{r} 1 \mathrm{~B})$ was used as a coated antigen in an indirect enzyme-linked immunosorbent assay (ELISA). The antigenicity and specificity of r1B against SAT 2 serotype-specific antibodies were assessed. Our results revealed that a protein concentration as low as $25 \mathrm{ng}$ could detect SAT 2-specific antibodies in ELISA. The results highlight the application of insect cells developed r1B protein in the detection of FMDV. Further studies are required to determine the ability of r1B for detecting other FMDV serotypes. 
Wael Elmenofy ${ }^{1}$, Ismail Mohamed ${ }^{1}$, Lamiaa El-Gaied ${ }^{1}$, Reda Salem ${ }^{1}$, Gamal Osman ${ }^{1,2,3^{*}} 5$

Mohamed Ibrahim 4

${ }^{1}$ Agricultural Genetic Engineering Research Institute (AGERI), ARC, Egypt

* Correspondence: geosman@uqu.edu.sa; Tel: 966595509073 
Foot-and-mouth disease virus (FMDV) is one of the most devastating animal viruses that affect

the livestock worldwide. The 1B capsid of FMDV has been widely used to detect and confirm the infection. In the present study, the sequence coding for 1B subunit of FMDV capsid was expressed 39 in insect cells using the baculovirus expression system under the polyhedrin (polh) promoter. The 40 expression of 1B capsid protein was validated in the culture filtrate of insect cells using SDSPAGE and western blotting. The culture filtrate containing recombinant $1 \mathrm{~B}$ capsid (r1B) was used as a coated antigen in an indirect enzyme-linked immunosorbent assay (ELISA). The antigenicity and specificity of r1B against SAT 2 serotype-specific antibodies were assessed. Our results revealed that a protein concentration as low as $25 \mathrm{ng}$ could detect SAT 2-specific antibodies in 45 ELISA. The results highlight the application of insect cells developed r1B protein in the detection 46 of FMDV. Further studies are required to determine the ability of r1B for detecting other FMDV serotypes.

Keywords Baculovirus expression system, Foot and Mouth Disease, capsid protein, protein expression.

\section{INTRODUCTION}

Foot-and-mouth disease (FMD) is considered as one of the most devastating diseases that affects 52 the livestock production (Kitchinget al., 2007; Arzt et al., 2010) and results in clinical signs such 53 as fever, general weakness, and vesicular sores on the tongue, gag, feet, and nipples (Grubman et 54 al., 2004; Arzt et al., 2011) FMD is caused by an aphthovirus, a viral genus of the family 55 Picornaviridae. There are seven distinct serotypes, A, O, C, Asia 1, and South African Territories 56 (SAT) 1, 2, and 3, representing FMDV (Belsham et al., 1993; Salem et al., 2019a). These serotypes 57 exhibit significant antigenic and hereditary assorted varieties, resulting in several subtypes and 58 genealogies. Accordingly, animals may become resistant to one serotype but still show sensitivity 59 to some other serotype (Domingo et al., 1993). Only serological tests could verify the presence of 60 FMDV. Serological FMDV tests are conducted for the following purposes: verify suspected cases, 61 certify individual animals for trade before travel, demonstrate the absence of disease, and 62 demonstrate vaccine effectiveness. FMDV serological tests are of two types: one that detects non63 structural protein (NSP) antibodies and the other detects structural protein (SP) antibodies. The 
tests based on SP detect antibodies triggered by infection or vaccination (Golding et al., 1976; 65 Hamblinet al., 1986; Hamblin et al., 1987; Salem et al. 2020). The SP-based tests are ideal for tracking the 66 immunity conferred by field vaccination, verifying past or ongoing disease in non-vaccinated 67 animals, certifying pre-transportation animals (for commercial purposes). The latest FMDV 68 detection techniques use inactivated live virus that presents some health risks. Moreover, these are 69 time-consuming, technically challenging, and have significant rate of false-positive reactions. The 70 structural proteins of FMDV are very complex and any alteration in their structures allows FMDV 71 to escape from the host immune system, which complicates the detection of antibodies against 72 each serotype (Carrillo et al., 2005). Therefore, having a sensitive, rapid, and reproducible laboratory 73 test to detect FMDV antibodies irrespective of serotypes is crucial.

The 1B capsid is a relatively conserved region among FMDV serotypes; however, certain 75 replacements in its amino acids have resulted in considerable antigenic diversity, suggesting that 76 1B capsid harbors important antigenic epitopes (Acharya et al., 1989). In the present study, we created 77 and expressed a recombinant 1B capsid protein to be used as a coating antigen in a simple local 78 indirect ELISA for detecting antibodies to FMDV, regardless of its serotype and as an alternative 79 to inactivated FMD viral antigen to confirm previous or ongoing infection in non-vaccinated 80 animals and to certify animals beforehand. Amino acid sequence alignments of these capsid 81 proteins revealed that $1 \mathrm{~B}$ capsid is the most highly conserved among several FMDV subtypes. We 82 believe that 1B capsid could be used to detect FMDV subtypes(Jamal et al., 2013; Salem et al., 83 $2019 b$ ). In the present study, the 1B capsid protein was expressed using the baculovirus/Sf9 cell 84 expression system. The construct was designed to direct the secretion of the recombinant protein 85 into cell culture media. We hypothesized that the secretion of recombinant protein could minimize 86 the misfolding of nascent peptides, thus reducing the likelihood of the protein to aggregate. 87 Furthermore, we believe that the expression in insect cells allows for post translation modifications 88 that could trigger a stronger immune response than that obtained from proteins expressed in a prokaryotic expression system.

The Sf9 cells were maintained at $27^{\circ} \mathrm{C}$ in Ex-Cell 420 serum-free medium (Sigma) 
Scientific). Antibodies used included monoclonal anti-His tag antibodies as the primary antibody 96 and horseradish peroxidase (HRP)-coupled anti-bovine IgG (Promega) as the secondary 97 $\begin{array}{ll}\text { antibody. } & 98\end{array}$

Designing, synthesis, and cloning of the 1B capsid gene 99

FMDV-SAT 2 isolate ( $\mathrm{gb} \mid$ AAZ83686) was used as the reference strain for cloning the 1B capsid 100 gene. In brief, the polypeptide that spans the 1B capsid flanked by 8 amino acid residues at the N- 101 terminus (the loop connecting 1A and 1B), and 30 amino acid residues at the C-terminus (loop 102 connecting 1B and 1C) were selected for expression. The corresponding nucleotide sequence that 103 codes for 1B polypeptide was subjected to codon usage optimization so that it better matched 104 Spodoptera frugiperda, the surrogate cells used for expression. The coding sequence of six 105 histidine residues (Histidine tag) and an enterokinase recognition sequence were also introduced 106 at the 3' end of the 1B expression cassette. Collectively, this polypeptide consists of 200 amino 107 acids. The 1B capsid expression cassette was cloned into the BssHII/PstI sites of the pFastBac 108 cloning vector and the expression of whole cassette was driven by the Ppol promoter. 109

Generation of recombinant bacmid in Escherichia coli 110

To generate recombinant bacmid that harbors the $1 \mathrm{~B}$ capsid gene, the recombinant 1B/pFastBac ${ }^{\mathrm{TM}} 111$ construct was transformed into Escherichia coli strain DH10Bac as per the manufacturer's 112 instructions (Life Technologies). Briefly, approximately $1 \mathrm{ng}$ of the 1B/pFastBac ${ }^{\mathrm{TM}}$ DNA in a total 113 volume of $5 \mu \mathrm{L}$ was transformed into $100 \mu \mathrm{L}$ of pre-chilled competent DH10Bac cells. The 114 mixture was kept on ice for $30 \mathrm{~min}$ and heat-shocked for $45 \mathrm{sec}$ at $42^{\circ} \mathrm{C}$. Immediately, the 115 transformed cells were chilled on ice for $2 \mathrm{~min}$. Around $900 \mu \mathrm{L}$ of Luria-Bertani broth (LB) 116 medium was added and the bacterial cells were incubated at $37^{\circ} \mathrm{C}$ with shaking for $4 \mathrm{~h}$. This 117 incubation period was sufficient to facilitate transposition of the recombinant cassette into the 118 bacmid mini-att $\operatorname{Tn} 7$ site within the lacZ $\alpha$-complementation region of the bacmid located in 119 DH10Bac genome. Five serial dilutions $\left(10^{-1}, 10^{-2}, 10^{-3}, 10^{-4}\right.$, and $\left.10^{-5}\right)$ of the obtained culture 120 were prepared and spread onto the LB agar plates $(50 \mu \mathrm{g}$ kanamycin, $7 \mu \mathrm{g}$ gentamicin, and $10 \mu \mathrm{g} 121$ tetracycline). Furthermore, X-Gal $(100 \mathrm{mg} / \mathrm{mL})$ and isopropyl $\beta$-d-1-thiogalactopyranoside 122 (IPTG) $(40 \mu \mathrm{g} / \mathrm{mL})$ were added to each plate to enable the screening of blue/white colonies. All 123 plates were again incubated at $37^{\circ} \mathrm{C}$ for $48 \mathrm{~h}$. 124 $\begin{array}{ll}\text { Verification of successful transposition of bacmid DNA } & 125\end{array}$ 
To verify successful transposition, 20 white colonies were selected for screening with PCR using 126 oligos M13/F (5'-GTTTTCCCAGTCACGAC-3') and M13/R (5'-CAGGAAACAGCTATGAC- 127 3'). These oligonucleotides flanked the insertion site of mini-att $\operatorname{Tn} 7$ in the recombinant bacmid. 128

Isolation of recombinant bacmid from $E$. coli

A polymerase chain reaction (PCR)-positive bacterial colony was picked and used to inoculate 2 130 $\mathrm{mL}$ LB medium supplemented with $50 \mu \mathrm{g} / \mathrm{mL}$ kanamycin, $7 \mu \mathrm{g} / \mathrm{mL}$ gentamicin, and $10 \mu \mathrm{g} / \mathrm{mL}$ tetracycline. The bacterial culture was incubated overnight at $37^{\circ} \mathrm{C}$ with shaking. Bacterial cells 132 were collected at $14,000 \times g$ for 1 min and suspended in $0.3 \mathrm{~mL}$ of Solution I $(15 \mathrm{mM}$ Tris- $\mathrm{HCl}$, 133 pH 8.0, $10 \mathrm{mM}$ EDTA, and $100 \mu \mathrm{g} / \mathrm{mL}$ RNase A). Cells were gently mixed and incubated at room 134 temperature (RT) for $5 \mathrm{~min}$. Approximately, $0.3 \mathrm{~mL}$ of Solution II $(0.2 \mathrm{~N} \mathrm{NaOH}, 1 \%$ sodium dodecylsulfate [SDS]) was added, followed by $0.3 \mathrm{~mL}$ of $3.0 \mathrm{M}$ potassium acetate ( $\mathrm{pH}$ 5.5). The 136 bacterial lysate was chilled on ice for $10 \mathrm{~min}$. The clear lysate, containing the bacmid DNA, was 137 separated from the insoluble cell debris by centrifugation for $10 \mathrm{~min}$ at $14,000 \times g$. The supernatant in a new microfuge tube containing $0.8 \mathrm{~mL}$ of absolute isopropanol. The DNA pellet was collected by centrifugation for $15 \mathrm{~min}$ at $14,000 \times g$ at RT and washed twice using 70\% ethanol. The DNA pellet was air-dried at RT for a few minutes and dissolved in $50 \mu \mathrm{L}$ Tris-EDTA (TE) buffer.

Transfection and propagation of recombinant baculovirus in Sf9 cells Recombinant bacmid DNA was used to transfect Sf9 cells according to the method described by O'Reilly et al., (1992). Briefly, $500 \mathrm{ng}$ bacmid DNA was mixed with Cellfection (Life Technologies). To this, $210 \mu \mathrm{L}$ of Excell-420 serum-free medium was added and the solution was kept at RT for $30 \mathrm{~min}$. This mixture was added dropwise to $\mathrm{Sf} 9$ cells $\left(5 \times 10^{9}\right.$ cells/plate), previously grown in a $35-\mathrm{mm}$ tissue culture 143 six-well plate. The cells were incubated at $27^{\circ} \mathrm{C}$ for $5 \mathrm{~h}$. Subsequently, the medium containing 146 Cellfection/bacmid DNA mixture was removed and replaced with Excell-420 serum-free medium, 147 supplemented with the appropriate antibiotics. Cells were incubated at $27{ }^{\circ} \mathrm{C}$ for $72 \mathrm{~h}$ in a 148 humidified incubator until the appearance of signs of viral infection. Successful transfection was 149 confirmed by observing the cytopathic effect $(\mathrm{CPE})$ due to viral infection under inverted light 150 microscopy.

\section{Detection of recombinant virus in infected Sf9 cells by PCR}

After the transfection of Sf9 cells with recombinant bacmid, it was necessary to verify the 153

presence of viral DNA in infected cells. Accordingly, PCR was used to detect viral-related 154 amplicons in Sf9 cells. PCR reactions were performed using three primers specific for the 1B 
capsid gene: C1B/F (5-CCT AAC ACC TCA GGT CTG GAG ACT CG-3), C1B/R1 (5-GGT GTA

CGA ATC GGT CAG CTT GC-3), and C1B/R2 (5-ATT GAT GAA CTG GTG AGG GTA GAG

G-3). The expected amplicon sizes using C1B-F/C1B-R1 and C1B-F/C1B-R2 are 162 bp and 306

bp, respectively. The PCR reactions were performed in a total volume of $25 \mu \mathrm{L}$. The PCR reaction

160

mixture was performed using the following contents: 10 pmol of each primer, $1 \mu \mathrm{L} \mathrm{MgCl}_{2}(25$

161

$\mathrm{mM}), 1.5 \mu \mathrm{L}$ of dNTPs (10 mM each), $2 \mu \mathrm{L}$ of DNA $(0.1-0.5 \mu \mathrm{g}), 5 \mu \mathrm{L}$ of $5 \times$ PCR reaction buffer,

162

and $0.5 \mu \mathrm{L}$ of GoflexiTaq DNA polymerase $(5 \mathrm{U} / \mu \mathrm{L})$ (Promega). The PCR cycles were as follow:

163

an initial denaturation cycle at $95^{\circ} \mathrm{C}$ for $3 \mathrm{~min}$, followed by a total of 35 cycles of denaturation at

164

$95{ }^{\circ} \mathrm{C}$ for $1 \mathrm{~min}$, annealing at $55^{\circ} \mathrm{C}$ for $1 \mathrm{~min}$, and extension at $72{ }^{\circ} \mathrm{C}$ for $1 \mathrm{~min}$; and final cycle at

165

$72^{\circ} \mathrm{C}$ for $7 \mathrm{~min}$ to allow the completion of primer extension.

Viral DNA isolation from infected Sf9 cells

The purpose of this experiment was to isolate the recombinant virus harboring the $1 \mathrm{~B}$ capsid

protein from Sf9 cells. To achieve this, $4 \mathrm{~mL}$ of the bacmid-infected Sf9 cells was spun down and

the cells were collected and dissolved in $500 \mu \mathrm{L}$ double distilled water $\left(\mathrm{ddH}_{2} \mathrm{O}\right)$. Recombinant

virions were released from Sf9-infected cells by incubation in $0.1 \mathrm{M} \mathrm{Na}_{2} \mathrm{CO}_{3}$ at $37^{\circ} \mathrm{C}$ for $1 \mathrm{~h}$. The

solution was neutralized to $\mathrm{pH} 8.0$ with few drops of $1.0 \mathrm{M} \mathrm{HCl}$ and subsequently treated with 45

$\mu \mathrm{g} / \mathrm{mL}$ RNase A at $37{ }^{\circ} \mathrm{C}$ for $10 \mathrm{~min}$. The solution was incubated in $1 \%$ SDS and treated with 250

$\mu \mathrm{g} / \mathrm{mL}$ Proteinase $\mathrm{K}$ for $1 \mathrm{~h}$ at $37^{\circ} \mathrm{C}$. The solution was extracted twice with Tris-EDTA (TE)-

saturated phenol:chloroform:isoamyl alcohol mixture $(25: 24: 1$ [v/v/v]), followed by

175 chloroform:isoamyl alcohol $(24: 1[\mathrm{v} / \mathrm{v}])$ extraction. The DNA was collected in 2.5 volume of icecold $97 \%$ ethanol in the presence of $1 / 10$ volume $3.0 \mathrm{M} \mathrm{NaOAc}, \mathrm{pH} \mathrm{5.2,} \mathrm{for} 10 \mathrm{~min}$ at 14,000 rpm. The DNA pellet was washed twice with $70 \%$ ethanol, recollected, and dissolved in $50 \mu \mathrm{L}$ TE.

To check the expression of 1B capsid protein in viral-transfected Sf9 cells, the released 
capsid protein. The expression of 1B capsid protein was evaluated by western blotting using monoclonal antibodies raised against $6 \times$ His-residues. In brief, cellular (C) and secretory (S) proteins were separated on $12 \%$ SDS-PAGE and the proteins were transferred onto a membrane (Immobilon ${ }^{\circledR}$ PVDF membrane; Millipore Corporation, Bedford, MA, United States) using a trans-blot apparatus (Bio-Rad), as described by (Towbin et al., 1979). The protein gel was incubated in the transfer buffer for $20 \mathrm{~min}$, and the membrane was activated by soaking in ethanol for a few seconds. The membrane was washed with transfer buffer for $20 \mathrm{~min}$ and the protein was transferred to the membrane using a vertical mini-blotter at $25 \mathrm{~V}$ overnight. After the transfer was complete, the membrane was removed and blocked in TBS (50 mM Tris- $\mathrm{Cl}[\mathrm{pH} 7.5]$ and $150 \mathrm{mM}$ $\mathrm{NaCl}$ ) containing 5\% BSA and $0.05 \%$ Tween-20 for 1 hour. The blocking buffer was discarded and replaced with TBS containing $10 \mu \mathrm{L}$ of anti-His tag antibodies, and the membrane was incubated overnight at RT. The membrane was washed thrice with TBST, 5 min each, and incubated in TBS containing $4 \mu \mathrm{L}$ of anti-mouse universal antibodies and kept overnight at RT. The membrane was washed thrice with TBST, as described above. Freshly prepared NBT/BCIP in alkaline phosphate buffer was added to the membrane and left at RT with agitation until the appearance of the purple band(s), indicating the locations of the specific protein(s).

The sensitivity of recombinant capsid protein r1B to capture the FMDV antibodies in the serum of ng and seeded in ELISA plates using $100 \mu \mathrm{L} /$ well in duplicate (4 times) for each concentration. plus $5 \%$ non-fat milk and 3\% BSA) was added (100 $\mu \mathrm{L} /$ well) to block the free residual spaces. 
PBST and $100 \mu \mathrm{L}$ of TMB-ELISA substrate (KPL) was added per well. To stop the reaction, 100

The deduced amino acid sequence of 1B capsid protein of an Egyptian SAT-2 isolate 226 ( $\mathrm{gb}$ |AAZ83686) was used to determine the relatedness of several FMDV isolates, representing the six prevalent FMDV subtypes. Our data revealed that subtype-O was the most divergent when 228 compared with other subtypes in our previous study (Salem et al., 2019a). The 1B capsid protein 229 was selected for the heterologous expression in insect cells and for antibody production, owing to 230 its high sequence homology among several FMDV subtypes.

As illustrated in Figure 1, the expression cassette contains the coding sequence of the 1B capsid 232 protein, which was completely synthesized and its codon usage was altered to better match the 233 preferred codon profile of $S$. frugiperda (the source for Sf9 cell line). Furthermore, the pFastBac234 Dual cloning vector was modified to include the signal peptidase sipS-coding sequence under the 235 control of the $p 10$ promoter to facilitate the secretion of the recombinant 1B capsid. The coding 236 sequence of six His residues and an enterokinase recognition sequence were also introduced into the pFastBac-Dual vector and downstream from the 1B expression cassette. His-tag was used to 238 monitor the expression of 1B capsid protein and used for further protein purification (Fig. 1 and 239 2A).

Successful cloning of the SipS gene into pFastBac Dual vector before and after cloning of the 1B expression cassette was verified. Endonucleases BbSI and NsiI were used to release the SipS integration into the $\mathrm{pFastBac}-1 \mathrm{~B}$ recombinant plasmid of $5.9 \mathrm{~kb}$.

To verify the transfection of recombinant bacmid into Sf9 cells, the presence of $1 \mathrm{~B}$ coding sequence was detected by PCR. DNA extracted from transfected Sf9 cells was subjected to PCR 248 using two pairs of primers. As shown in Figure 3, PCR amplicons 162 bp and 306 bp, obtained 
by C1B-F/C1B-R1 and C1B-F/C1B-R2, respectively, were obtained. These results indicated the 250 successful transfection of the recombinant bacmid into Sf9 cells. 251

The culture filtrate of infected Sf9 cells was analyzed using SDS-PAGE to check the expression 252

of secretory 1B capsid protein. The expression of 1B capsid protein was evaluated by western 253 blotting using subtype SAT 2-specific antibodies. As shown in Figure 4A, a polypeptide of 22254 $\mathrm{kDa}$ was detected in the cell lysate of viral infected Sf9 cells, but not in non-transfected cells. The 255 identity of the 22-kDa polypeptide was confirmed by western blotting using SAT 2-specific 256 polyclonal antisera. The results of the western blotting showed that the predicted molecular mass 257 of $1 \mathrm{~B}$ protein $(22 \mathrm{kDa})$ was successfully detected using FMDV SAT 2-specific antibodies, 258 suggesting the correct molecular mass of 1B protein using the baculovirus expression system (Fig. 259 4B).

Indirect ELISA test

Serial dilutions ranging from 1:1 to 1:32 of P1 viral stock was used for coating in indirect

ELISA to capture the FMDV SAT 2-specific antibodies in collected antiserum sample that was previously validated in VSVRI as positive by VNT.

The highest ELISA signals were detected from the dilution 1:1 of media containing the recombinant 1B protein. The OD values gradually decreased from the dilution 1:2 to dilution 1:16; no positive reaction was noticed with dilution 1:32 (Fig. 5).

DISCUSSION

The primary aim of the present study was to express the 1B capsid polypeptide of FMDV in a soluble, less aggregated form, and evaluate its ability to detect the antibodies from FMDV-infected or -vaccinated animals. It was crucial to obtain the r1B capsid protein in a form capable of eliciting 273 an adequate immune response and producing highly specific antibodies in immunized mice. Prior studies have reported immunogenic properities of FMDV 1B protein (Voller, et al., 1976). Some 275 studies have suggested that, although exposed to the viral surface, the $\mathrm{N}$ terminal region of $1 \mathrm{~B}$ has 276 low antigenic potential (Lea et al. 1994; Curry et al., 1997). However, the $\mathrm{N}$ terminus of 1B has 277 been proven antigenic since it has no fixed position (Acharya, et al. 1989), and its structural 278 flexibility exposes some of the internal domains of the capsid proteins to the surface, allowing 279 them to become definite antigenic sites (Freiberg et al. 2001). Another report (Acharya, et al. 
1989) showed in a similar vein that amino acid substitutions in the 1B subunit result in a significant antigenic diversity that leads to changes in FMDV's pathogenicity and replication capacity. Thus, 282 even if some of the 1B N-termini sites are not accessible by Ab, the remaining accessible sites 283 seem adequate for ELISA detection (Freiberg et al. 2001).

To achieve this, the baculovirus/Sf9 cells (BacSf9) expression system was selected for expressing 285 the recombinant 1B capsid protein. Reasons for using BacSF9 system for protein expression 286 included 1) secretion into the growth medium; 2) production of less aggregated proteins with an increased probability of correct folding, and 3) post-translational modifications for better 287 antigenicity and specificity. Previously, the baculovirus expression system was successfully used to express different viral proteins such as the tomato yellow leaf curl virus coat protein (TYLCV) (Elgaied et al., 2017), Garlic mite-borne filamentous virus (GarMbFV) (Ardisson-Arau'jo et al. 2013), and glycoprotein E (gE) of the Egyptian BoHV-1.1 Abu-Hammad strain (rBac/gE-AbuH) (El-Kholy et al., 2013, Elgaied et al., 2020). Furthermore, recombinant proteins produced using this system were validated for their antigenticity. The recombinant proteins were successfully used to detect viruses from infected samples, especially when the virus was present in low titers and in mixed infection in plant hosts. As the $1 \mathrm{~B}$ capsid protein is the most highly conserved capsid subunit among several FMDV subtypes, it was selected for the heterologous expression and for further analysis. A compatible signal peptide/signal peptidase system that ensured complete processing and secretion of expressed proteins was designed. Based on a previous study (Ailor et al., 1999; Doel et al., 2003; Cao et al., 2009; Li et al., 2011; Salem et al., 2018), we selected the signal peptidase gene sipS from Bacillus subtilis. Accordingly, the pFastBac-Dual cloning vector was modified by inserting the sipS-coding sequence under the control of the p10 promoter. The sipS coding sequence was completely synthesized using the published sequence; however, its codons were altered to better match the preferred codon usage of S. frugiperda, the source for Sf9 cell line. Furthermore, a signal peptide (SP) compatible with the sipS peptidase was incorporated upstream of the 1B coding sequence (Fig. 1) to facilitate the processing and secretion of the recombinant protein. Typically, the SP was 15 to 25 amino acids in length and consisted of three distinct regions: a short positively charged residue followed by a stretch of hydrophobic residues and ending with a few small side-chain residues located at the -3 and -1 position from the peptidase cleavage site, usually aspartic acid. We followed these criteria when we designed our SP; however, the yield of secreted proteins using the SP/SipS signal peptidase was relatively low 
(Fig. 4). This was probably owing to the incomplete processing of SP; the SP was not completely well as the precursor polypeptides. However, the anti-His antibody detected a single polypeptide corresponding to the correct size of 1B capsid subunit in western blotting; no other protein bands 316 were detected (Fig. 4B, lane PW). The purified r1B capsid was used as a coated antigen in ELISA. The results showed that IB capsid protein-based indirect ELISA was able to detect anti-FMDV 318 SAT 2 antibodies in sera raised against virus particles in all diluted samples. No signals were 319 detected in all negative samples isolated from mock infected Sf9 cells. The clarified extract from 320 cells culture filtrate used for coating the ELISA plates did not show interference or loss in specificity, suggesting no need for further purification (Fig. 5).

\section{CONCLUSION}

In this study, the insect developed 1B-based ELISA has great potential to adapt to a quick penindirect ELISA as a coating antigen. In addition, the purified protein may be used for raising a inactivated FMDV antigen in diagnostic assays, which will also decrease the risks of biosecurity

Funding: This work is supported by the Academy of Scientific Research and Technology (ASRT),

\section{Competing Interests}

The authors declare there are no competing interests.

* R. S., W. E., and I. M., conception and designed the experiments,

*M. I., W. E., and G. O., analysed the data and wrote the paper. 
Acknowledgements: The authors would like to thank Dr. Alaa El-Kholy for providing us with 343

$\begin{array}{ll}\text { FMDV SAT } 2 \text { specific antibodies. } & 344\end{array}$

REFERENCES

346

Acharya R, Fry E, Stuart D, Fox G, Rowlands D, Brown F. 1989. The three-dimensional 347 structure of foot-and-mouth disease virus at 2.9 A resolution. Nature. 337: 709-716

Acharya, R. Fry, E. Stuart, D. Fox, G. Rowlands, D. \& Brown, F. 1989. The three-dimensional structure of footand-mouth disease virus at 2.9 A resolution. Nature337, 709-716.

Ailor E, Pathmanathan J, Jongbloed JD, Betenbaugh MJ. 1999. A bacterial signal peptidase 351 enhances processing of a recombinant single chain antibody fragment in insect cells. Biochemical and Biophysical Research Communications. 255: 444-450.

Ardisson-Arau'jo DM, Rocha JR, da Costa, MH, Bocca AL, Dusi AN, Resende RO, Ribeiro

BM. 2013. A baculovirus-mediated strategy for full-length plant virus coat protein expression and purification. Virology Journal. 10:262-270.

Arzt J, Juleff N, Zhang Z, Rodriguez L L. 2011. The pathogenesis of foot-and-mouth disease I: Viral pathways in cattle. Transboundary and Emerging Diseases. 58: 291-304.

Arzt J, White W R, Thomsen B V, Brown C. 2010. Agricultural diseases on the move early in 359 the third millenium. Veterinary Pathology. 47: 15-27.

Belsham G. J. 1993. Distinctive features of foot-and-mouth disease virus, a member of the picornavirus family; aspects of virus protein synthesis, protein processing and structure. Progress in Biophysics and Molecular Biology. 60: 241-261.

Cao YM, Lu ZJ, Sun JC, Sun P, Guo JH, Liu ZX. 2009. Synthesis of foot-and-mouth disease virus empty capsids in insect cells through acid-resistant modification. Science Agricola Sinica. 42:1069-1077.

Carrillo C, Tulman E R, Delhon G, Lu Z, Carreno A, Vagnozzi A, Kutish G F, Rock DL. 367 2005. Comparative genomics of foot and mouth disease virus.J. Virol. 79: 6487-6504

Curry, S. Fry, E. Blakemore, W. Abu-Ghazaleh, R. Jackson, T. King, A. Lea, S. Newman, J. 369 \& Stuart, D. 1997. Dissecting the roles of VP0 cleavage and RNA packaging in picornavirus capsid stabilization: the structure of empty capsids of foot-and-mouth disease virus. J. Virol.71 (12), 9743-9752.

Doel TR. 2003. FMD vaccines. Virus Research. 91: 81-99. 
Domingo E, Escarmı's C, Martı́nez-Salas E, Martı́n-Hernandez AM, Mateu MG, 373 Martı́nez MA. 1993. Picornavirus variation. In: Carrasco, L., Sonenberg, N., Wimmer, E. 374 (Eds.), Regulation of Gene Expression in Animal Viruses. Plenum, New York. 255-281.

El-Gaied, L., Salem R, Elmenofy W. 2017. Expression of tomato yellow leaf curl virus coat 376 protein using baculovirus expression system and evaluation of its utility as a viral antigen. 3 Biotech. 7: 269.

El-Gaied, L., Mahmoud, A., Salem, R., Elmenofym W., Saleh, I., Abulreesh, H., Arif, I., 379 Osman, G. 2020. Characterization, cloning, expression and bioassay of vip3 gene isolated from an Egyptian Bacillus thuringiensis against whiteflies. Saudi J. Biol. Sci. https://doi.org/10.1016/j.sjbs.2019.12.013

EI-Kholy AA, Eman RA, Rady DI, Elseafy MM. 2013. Baculovirus expression and diagnostic utility of the glycoprotein E of bovine herpesvirus-1.1 Egyptian strain "Abu-Hammad". Journal of Virological Methods. 191: 33-40.

Freiberg, B. Hohlich, B. Haas, B. Saalmuller, A. Pfaff, E. \& Marquardt, O. 2001. Typeindependent detection of foot-and-mouth disease virus by monoclonal antibodies that bind to amino-terminal residues of capsid protein VP2. J. Virol. Methods92 (2), 199-205, https://doi.org/10.1016/S0166-0934(00)00287-1

Golding SM, Hedger R S, Talbot P, Watson J. 1976. Radial immunodiffusions and serum 390 neutralisation techniques for the assay of antibodies to swine vesicular disease. Res. Vet. Sci. 20: $142-147$

Grubman M J, Baxt B. 2004. Foot-and-mouth disease. Clinical Microbiology Reviews. 17: 465393 493.

Hamblin C, Barnett I T R, Hedger R S. 1986. A new enzyme-linked immunosorbent assay 395 (ELISA) for the detection of antibodies against foot-and-mouth disease virus I. Development and method of ELISA. J. Immunol. Methods. 93: 115-121

Hamblin C, Kitching R P, Donaldson A I, Crowther JR, Barnett ITR. 1987. Enzyme-linked 398 immunosorbent assay (ELISA) for the detection of antibodies against foot-and-mouth disease virus.: III. Evaluation of antibodies after infection and vaccination. Epidemiol. Infect. 99: 733-744

Jamal SM, Belsham GJ. 2013. Foot-and-mouth disease: past, present and future. Veterinary 402 Research. 44: 116. 
Kitching P, Hammond J, Jeggo M, Charleston B, Paton D, Rodriguez L, Heckert R. 2007.404 Global FMD control-Is it an option? Vaccine. 25: 5660-5664.

Lea, S. Hernandez, J. Blakemore, W. Brocchi, E. Curry, S. Domingo, E. Fry, E. Abu- hazaleh, R. King, A. 406 Newman, J. Stuart, D. \& Mateu, M. G. 1994. The structure and antigenicity of a type C foot-and-mouth disease virus. Structure,2, 123-139, https://doi.org/10.1016/S0969-2126 (00)00014-9

Li Z. Yin X. Yi Y. Li X. Li B. Lan X. Zhang Z. Liu J. 2011. FMD subunit vaccine produced 409 using a silkworm-baculovirus expression system: protective efficacy against two type Asia1 isolates in cattle. Veterinary Microbiology. 149: 99-103.

O'Reilly D R, Miller L K, Luckow V A. 1992. A Laboratory Manual, Freeman, W. H. Company, Baculovirus Expression Vectors. New York. 12-23.

Salem R, El-Kholy A A, Ibrahim M. 2019b. Eight novel single chain antibody fragments 414 recognising VP2 of foot-and-mouth disease virus serotypes A, O, and SAT 2. Virology. 533: $145-154$

Salem R, Arif A I, Salama M, Osman G H. 2018. Polyclonal antibodies against the recombinantly expressed coat protein of the Citrus psorosis virus. Saudi J. Biol. Sci. 25: 733738

417

Salem R, Assem K S, Omar A O, Khalil AA, BasryA M, Waly R F, Samir N, El-Kholy A A. 2020. Expressing the immunodominant projection domain of infectious bursal disease virus fused to the fragment crystallizable of chicken IgY in yellow maize for a prospective edible vaccine. Molecular Immunology. 118C，132-141

Salem R, El-Kholy A A, Omar O A, Abu el-naga M N, Ibrahim M, Osman G. 2019a. Construction, Expression and Evaluation of Recombinant VP2 Protein for serotypeindependent Detection of FMDV Seropositive Animals in Egypt. Scientific Reports. 9:10135,

Towbin H, Staehelin T, Gordon J. 1979. Electrophoretic transfer of proteins from polyacrylamide gels to nitrocellulose sheets: procedure and some applications. Proceedings of the National Academy of Science of the USA. 76: 4350-4354.

Voller, A. Indwell, O.E. \& Bartlett 1976. A. Enzyme immunoassays in diagnostic medicine: theory and practice. Bulletin of the World Health Organization, 53, 55-65 
Figure 1

figure 1

Figure 1: The recombinant cassette, shows coding sequence of the $1 \mathrm{~A}-1 \mathrm{~B}$ inter-peptide (1A1B-IP is a short polypeptide linker that connects VP4/1A and VP2/1B, the signal peptide (SP), histidine tag, enterokinase recognition sequence and the 1B capsid protein, in fusion with a signal peptide.

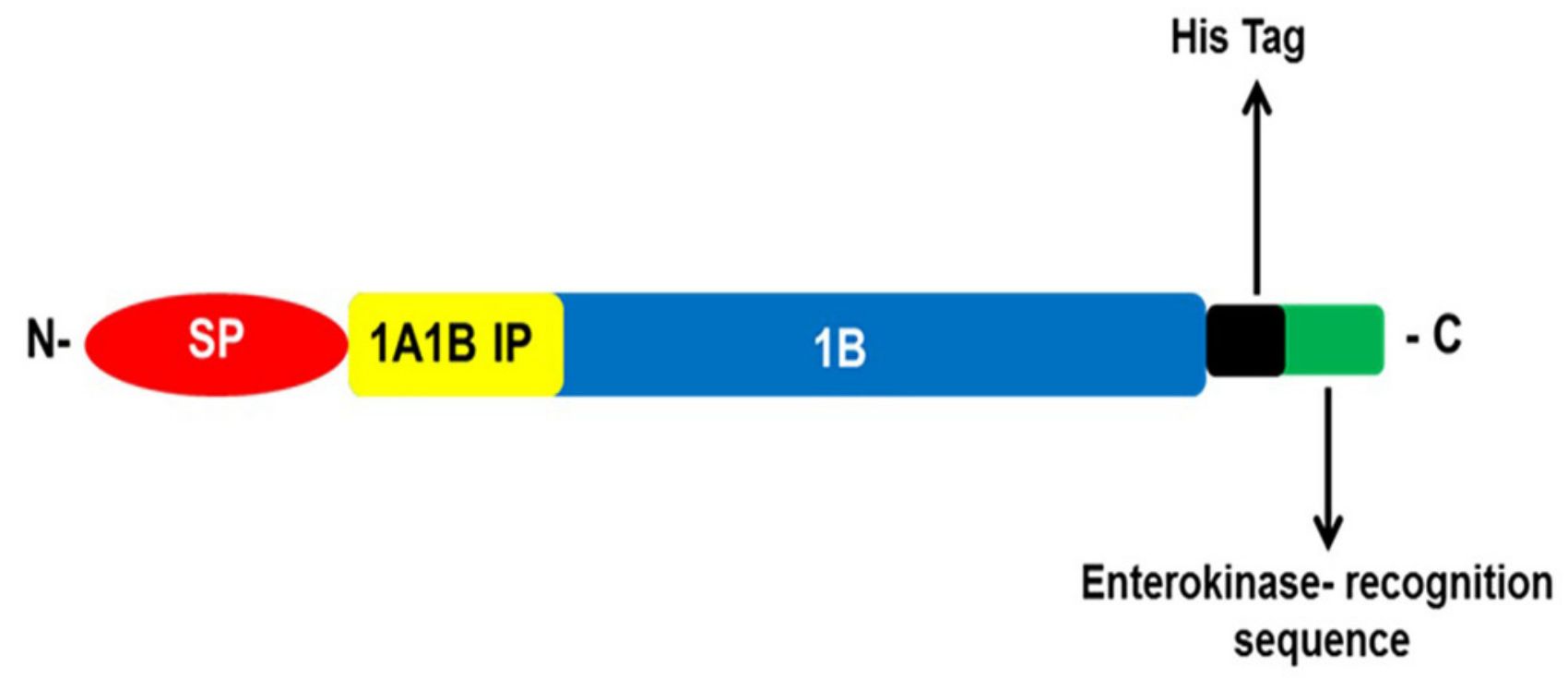




\section{Figure 2}

figure 2

Figure 2: Construction of pFastBacDual vector charboring the 1B cassette. (A) Plasmid map shows the recombinant cassette that was cloned downstream from the Ppol promoter of the modified pFastBac-Dual vector. (B) 1\% agaros gel shows the verified recombinant plasmid using restriction enzyme digestion. $\mathrm{M}$ : $1 \mathrm{~kb}$ ladder. RP: Recombinant plasmid harboring the $1 \mathrm{~B}$ cassette and the SipS gene. Arrows show the molecular size $(\mathrm{kb})$ for both SipS gene $(0.57 \mathrm{~kb})$ and the pFastBac-1B vector $(5.9 \mathrm{~kb})$.

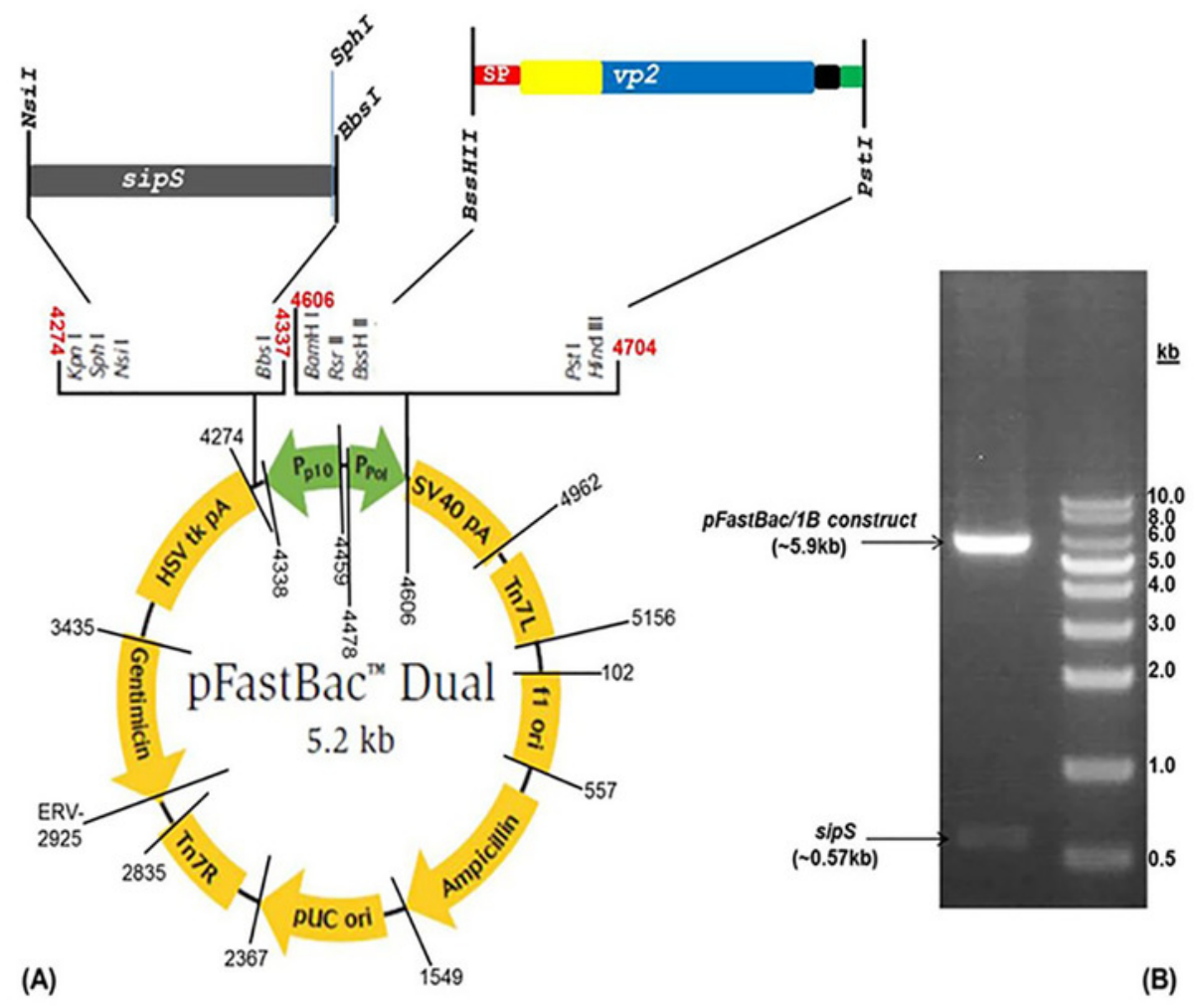




\section{Figure 3}

figure 3

Figure 3 PCR detection of recombinant bacmid in infected S9 cells. M. $1 \mathrm{~kb}$ Ladder, lane 1 :

Total DNA from Sf9 cells (mock infection), lane 2. Total DNA from infected Sf9 cells, lane 3:

pFastBacDual vector harboring the 1B cassette (positive control), lane 4: Total DNA from

healthy Sf9 cells (mock infection), lane 5: Total DNA from infected Sf9 cells and lane 6:

pFastBacDual vector harboring the $1 \mathrm{~B}$ cassette (Positive control).

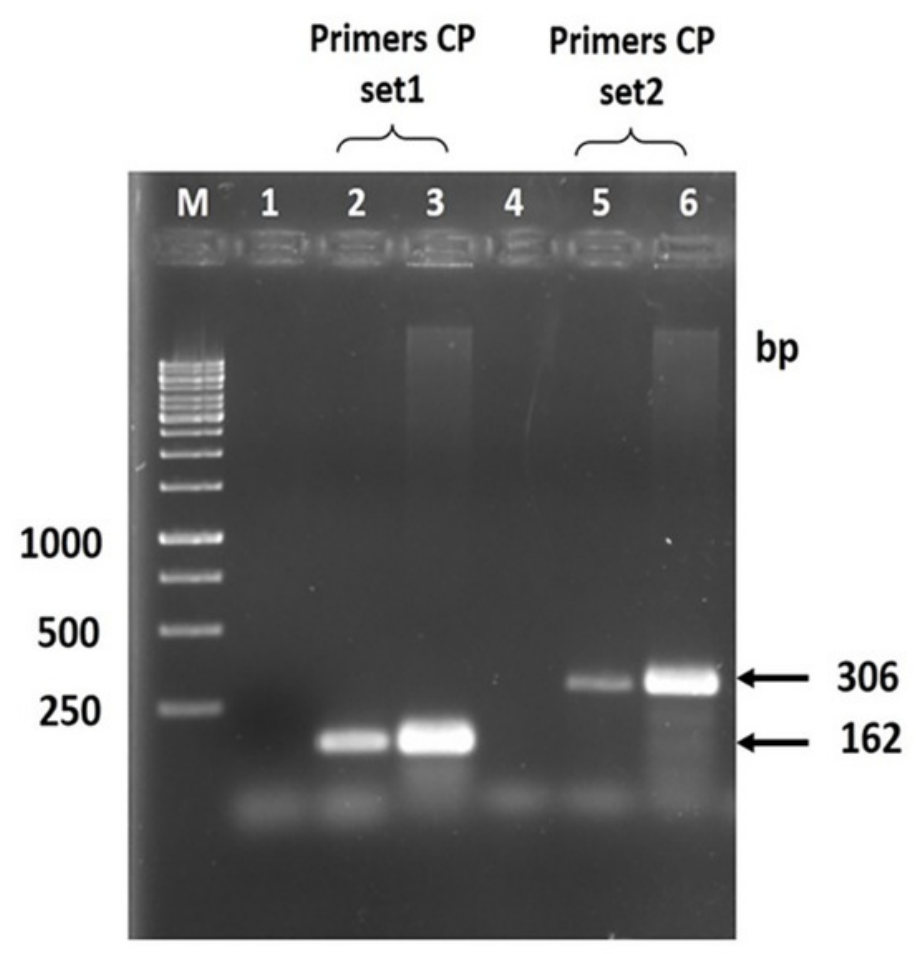




\section{Figure 4}

figure 4

Figure 4: Protein analysis of 1B expressed in SF9 cells. (A) SDS-PAGE (12\%) of total protein extracted from culture filtrate of infected Sf9 cells using recombinant virus. M: Page Ruler prestained protein ladder. C-: Cells lysate extracted from mock infected Sf9 cells. S: Total protein of cells lysate extracted from viral infected Sf9 cells. P: Total protein extracted from culture filtrate (media) of infected Sf9 cells. (B) Western blot analysis of the expressed 1B capsid protein in Sf9 cells. PW: Secreted proteins in culture filtrate of Sf9 infected cells, C+: Positive control. Arrows show a clear protein band at $\sim 22 \mathrm{kDa}$ corresponding to $1 \mathrm{~B}$ capsid protein in both SDS-PAGE gels and western blot.

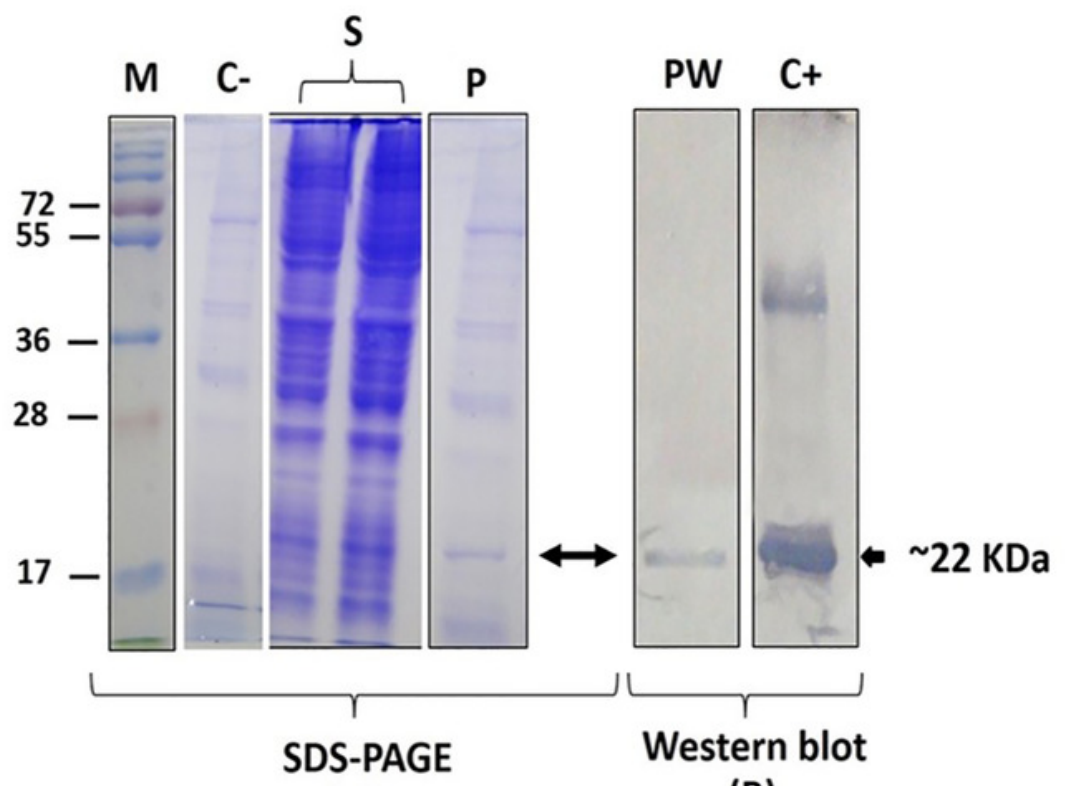

(A)

(B) 
Figure 5

figure 5

Figure 5 Antigen sensitivity of r1B using indirect ELISA. The sensitivity of the r1B capsid protein against FMDV SAT 2 specific antibodies was tested using ELISA assays. The Y-axis represents the optical density value (OD) measured at $450 \mathrm{~nm}$. The $x$-axis represents serial dilutions of the Sf9-culture filtrate contain the r1B protein. The error bar represents $5 \%$ more or less of the ELISA reading value.

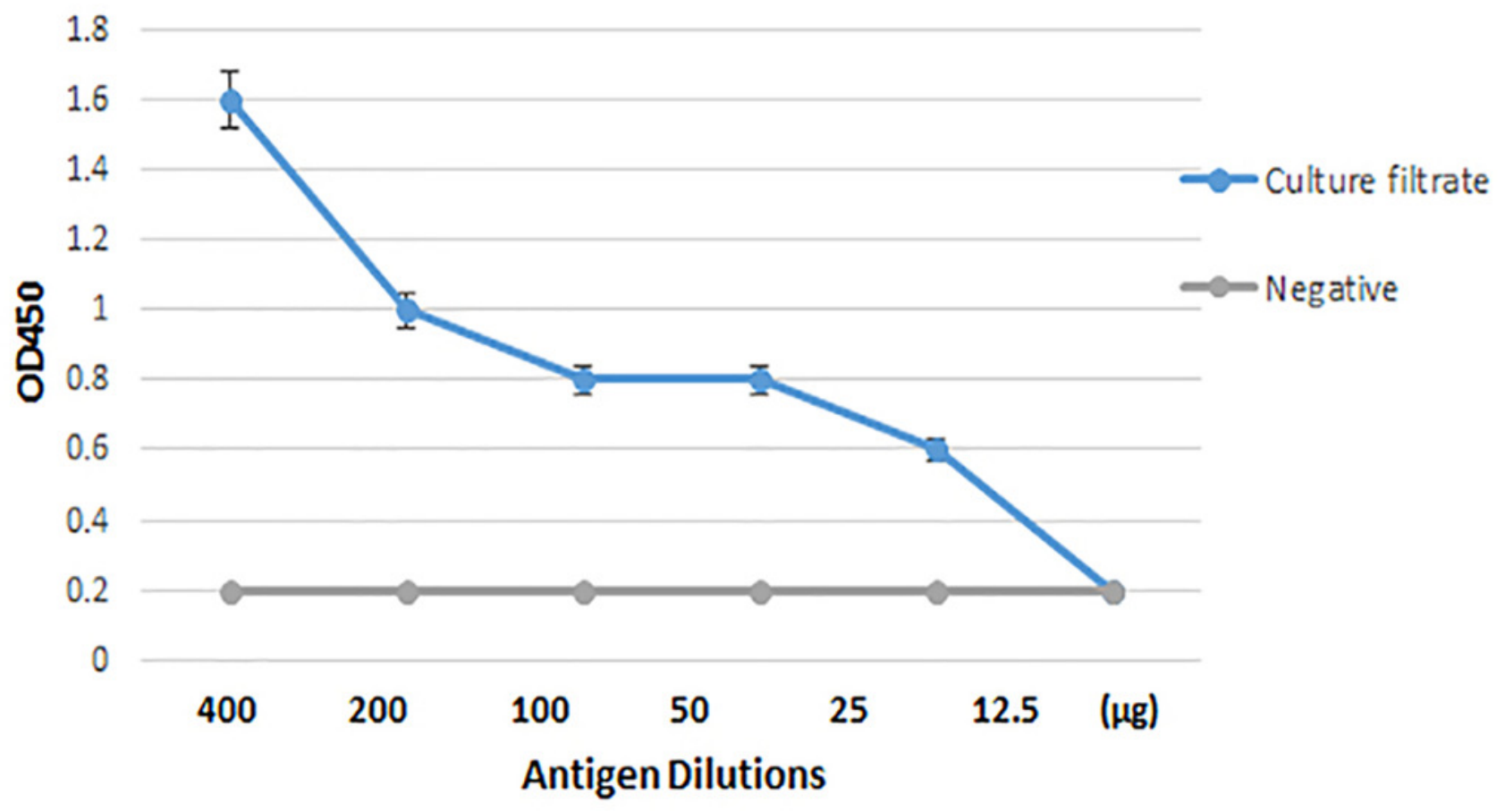

